\title{
Laboratory Study on Properties of Tire Crumb Rubber Modified
}

\section{Bituminous Mixture}

\author{
Yuming Dong ${ }^{1, a}$, Yiqiu Tan ${ }^{2, b}$ \\ ${ }^{1}$ School of Transportation Science \& Engineering, Harbin Institute of Technology, Harbin, China \\ 150090. \\ ${ }^{2}$ School of Transportation Science \& Engineering, Harbin Institute of Technology, Harbin, China \\ 150090. \\ adongdym@163.com, byiqiutan@163.com
}

Key words: Crumb rubber, Mixture, Rutting resistance, Cracking resistance.

\begin{abstract}
This paper investigates the laboratory properties of tire crumb rubber modified (CRM) bitumen mixture. Two types of mixtures containing two binders (pen90 bitumen; CRM bitumen) were used to produce Marshall Sample and determine optimum content. Mechanical performances of bituminous mixtures were evaluated by Chinese wheel rutting test (WRT), 3point beam bending test (3P-BBT) at low temperature, indirect tensile Strength test (ITST) at freezing-thawing cycles. Superpave gyratory compactor (SGC) specimens also were prepared for modulus test. Resilient modulus $(E)$ data were obtained by unconfined uni-axial compression test according to the specification of China. Dynamic modulus $\left(E^{*}\right)$ data were obtained by Simple Performance Test (SPT). Two temperatures were used at dynamic modulus test. The results indicate that CRM bituminous mixture performs better than referenced bituminous mixture on viscoelastic behavior, rutting resistance, cracking resistance and moisture stability.
\end{abstract}

\section{Introduction}

In recent years, crumb rubber modification within a wide range of contents and sizes has been done to improve asphalt performance at pavement service temperatures. The ability of crumb rubber to improve the mix properties depends on many factors, including the incorporation technology, nature of the rubber, size of the rubber particles, and the percentage of rubber in the mix and its reaction time with asphalt. Field studies have shown that crumb rubber modification of asphalts can improve the asphalt pavement performance ${ }^{[1,2,3,4]}$. The use of crumb rubber modifiers with asphalt binders seems to enhance the fatigue resistance, as illustrated in a number of studies ${ }^{[5,6,7,8]}$. The improved performance of asphalt rubber pavements compared with conventional asphalt pavements has partly resulted from improved rheological properties of the asphalt-rubber binder. However, optimum crumb rubber content still needs to be determined for different crumb rubber contents. Moreover, the viscoelastic properties of CRM asphalt mixture also are investigated by SPT.

\section{Design of Mixture}

Marshall Method still is used for mix design of the crumb rubber modified (CRM) asphalt mixture. For this method, mix design includes materials selection, gradations selection, optimum asphalt contents, and verification of performance. 


\section{Properties of original materials}

The base binder pen $90^{\#}$ is used to modify asphalt with tire scrap crumb rubber. The mixing processing over $45 \mathrm{~min}$ at $180^{\circ} \mathrm{C}$ is adopted in the laboratory. According to the construction technical specification for asphalt pavement of highway (JTG F40-2004) in China, the technical parameters of $90^{\#}$ pen base asphalt meet to its specification. The parameters of CRM asphalt is shown in table1.

Table1 Testing parameters of CRM bitumen

\begin{tabular}{|c|c|c|c|}
\hline Test Item & CRM bitumen & requirement & methods \\
\hline Penetration@25ㄷ $(0.1 \mathrm{~mm})$ & 64.5 & $40-80$ & T0604 \\
\hline Ductility@ $5^{\circ} \mathrm{C}(\mathrm{cm})$ & 17.4 & $>10$ & T0605 \\
\hline Softening Point $\left(\mathrm{T}_{\mathrm{R} \& \mathrm{~B}}\right)\left({ }^{\circ} \mathrm{C}\right)$ & 57.6 & $>47$ & T0606 \\
\hline Elastic Recovery（\%） & 81.1 & $>55$ & T0662 \\
\hline Br. Viscosity@180 $180^{\circ} \quad(\mathrm{Pa} \cdot \mathrm{s})$ & 2.44 & $1.0-4.0$ & T0611 \\
\hline \multicolumn{4}{|c|}{ Thin Film Oven Test (TFOT) } \\
\hline Mass Loss $(\%)$ & -0.23 & $<0.4$ & T0610 \\
\hline Penetration Ratio (\%) & 88.9 & $>80$ & T0604 \\
\hline Ductility Ratio@5 $\mathrm{C}(\%)$ & 64.8 & $>40$ & T0605 \\
\hline Softening Point Ratio（\%) & 101.2 & $<110$ & T0606 \\
\hline
\end{tabular}

The addition of tire crumb rubber improves the properties of virgin bitumen. The limestone coarse aggregate is adopted, and must be clean, hard, the lower F\&E and the manufactured fine aggregate is adopted, and must be clean, higher S.E; the low silica stone is made for the filler to be fine enough, clean and the lower plastic index.

\section{Gradation Design}

The different grades are used for the CRM asphalt mixture and the usual asphalt mixture in this study, and the nominal maximum aggregate size (NMAS) is $13.2 \mathrm{~mm}$. Considering rubber grains distributed in CRM binder, the two mixtures are different from the passing percent of $4.75 \mathrm{~mm}$ sieve size. The one of CRM-AC-13 is $30 \%$, and the one of AC-13 is $45 \%$. The rubber grain can be a fine aggregate in the CRM mixture. The passing percentages of sieves in the two mixtures are shown the following table.

Table2 Passing percentage of mineral mixtures (\%)

\begin{tabular}{c|c|c|c|c|c}
\hline Sieve Sizes(mm) & 13.2 & 9.5 & 4.75 & 2.36 & 0.075 \\
\hline CRM-AC & 95 & 65.6 & 30 & 23.5 & 7 \\
\hline AC & 95 & 70 & 45 & 30 & 5 \\
\hline
\end{tabular}

The gap grade based on the skeleton compact theory with multi-filling state is adopted to improve the rutting resistance in this study. Thus the rutting resistance, the thermo-cracking resistance and the water resistance must be considered for mix design in Beijing.

\section{Selection of optimum bitumen content}

Based on predicting asphalt content, the distance of $0.5 \%$ is adopted, and five contents are selected for Marshall Specimens with 75 hammers dual sides. Based on the volumetric method, the void content is a main parameter for determining asphalt content. Generally, the objective void air content is considered as $4 \%$, and the void mineral aggregate (VMA) is more than $15 \%$ for the NMAS $13.2 \mathrm{~mm}$ mixture. In theory, the crumb rubber is beneficial to extend pavement life, however this make the construction of HMA difficult. Thus CRM asphalt mixture need the higher mixing 
temperature for good workability. The characteristics of two mixtures, including rutting resistance, cracking resistance, moisture stability, static modulus, and dynamic modulus, were investigated in this study.

\section{Properties of CRM Mixture}

The performances of CRM asphalt mixture also include the rutting resistance at high temperature condition, the cracking resistance at low temperature condition, moisture sensitivity at humid regions, and mechanical strength. Marshall Test, wheel tracking test, 3 point beam bending test (3P BBT), and Indirect Tensile Strength Test are adopted for evaluating performances.

\section{Stability at the high temperature}

The high temperature properties are evaluated by Marshall Stability test and wheel tracking test for mixture in China. As the following table shows, rutting resistance of CRM mixture is higher than AC, especially dynamic stability.

Table3 Results of high temperature properties

\begin{tabular}{c|c|c}
\hline Test Parameter & AC & CRM-AC \\
\hline $\mathrm{MS} / \mathrm{kN}$ & 8.6 & 8.8 \\
\hline $\mathrm{FV} / \mathrm{mm}$ & 2.1 & 2.9 \\
\hline $\mathrm{DS} @ 60^{\circ} \mathrm{C} /($ cycles $/ \mathrm{mm})$ & 1290 & 3810 \\
\hline
\end{tabular}

The Marshall Stability (MS) and the Flow Value (FV) have no obvious differences for two mixes.

\section{Cracking resistance at the low temperature}

The 3 point beam bending test is used to evaluating the cracking resistance of bituminous mixture in China. The maximum bending strain of two mixtures is respectively $2200 \mu \varepsilon$ and $3568 \mu \varepsilon$ over the $2000 \mu \varepsilon$ standard value. The crumb rubber modifier effectively improves the low temperature property of bituminous mixture.

\section{Moisture sensitivity}

The residue stability (RS) of Marshall Test and the tensile strength ratio (TSR) of indirect tensile strength test (ITST) are used to evaluating the moisture resistance for bituminous mixture in China.

Table4 Results of moisture sensitivity

\begin{tabular}{c|c|c}
\hline Test Parameter & AC & CRM-AC \\
\hline RS $/ \%$ & 81.3 & 92.3 \\
\hline TSR $/ \%$ & 78.8 & 82.5 \\
\hline
\end{tabular}

The above test results show that adding of crumb rubber is beneficial to the moisture resistance.

\section{Resilient modulus}

Static resilient modulus of road material is the most important input parameter in designing asphalt pavement structure in China, based on multi-layer elastic system theory. The resilient modulus was measured and its elastic mechanical characteristic was investigated.

Resilient modulus test uses the diameter $\varphi 100 \mathrm{~mm}$ and height $100 \mathrm{~mm}$ samples, and these samples are made by gyratory compactor. Axial compression load is applied on unconfined specimen by sequence at $20^{\circ} \mathrm{C}$ condition. Six recycles of loading and unloading are applied on specimens after the first stage of steady compressing, and the peak value of every recycle of loading and unloading is 0.1-0.6 times as the strength. After stress and strain are determined, the resilient modulus may be calculated. The samples of CRM-AC and reference asphalt mixture AC are prepared for resilient modulus test. Testing data of resilient modulus are shown in the following table after statistically processing. 
Table5 Resilient Modulus and Strength @20 ${ }^{\circ} \mathrm{C}(\mathrm{MPa})$

\begin{tabular}{c|c|c|}
\hline Mixture types & AC & CRM-AC \\
\hline Resilient Modulus $(\mathrm{MPa})$ & 1198 & 1587 \\
\hline Axial Strength $(\mathrm{MPa})$ & 3.44 & 6.03 \\
\hline
\end{tabular}

Obviously, the resilient moduli and the axial strengths of three CRM mixtures are higher than reference mixture. This result demonstrates that the tire scrap crumb rubber is very beneficial to improve stiffness of asphalt mixture. In unconfined compression load, the more mastic fluidized structure is weaker than the more aggregate skeleton structure.

\section{Dynamic modulus}

Dynamic moduli of pavement material can perform the real behavior under the traffic load. The dynamic moduli of CRM-AC and AC are tested in this study. Dynamic moduli at the two testing temperature are determined by AMPT. The complex modulus and phase angle are obtained.

The following tables show the parameters achieved by for CRM-AC and usual AC. Dynamic moduli of CRM-AC are higher than the one of $\mathrm{AC}$ at the same temperature. As the data at $40^{\circ} \mathrm{C}$ shows, $\mathrm{E}^{*}$ of CRM mixture is $3154 \mathrm{Mpa}$ and $\mathrm{E}^{*}$ of AC mixture is $2127 \mathrm{Mpa}$ under $25 \mathrm{~Hz}$ frequency; $\mathrm{E}$ of CRM mixture is $1146 \mathrm{MPa}$ and $\mathrm{E}$ of usual mixture is $480 \mathrm{Mpa}$ under $0.1 \mathrm{~Hz}$ frequency.

Table6 Results of CRM-AC and AC@ the lower temperature

\begin{tabular}{c|c|c|c|c|c|c}
\hline \multicolumn{7}{c}{ CRM-AC } \\
\hline Loading frequency (Hz) & 25 & 10 & 5 & 1 & 0.5 & 0.1 \\
\hline Dynamic modulus (MPa) & 10823 & 8598 & 7289 & 4682 & 3889 & 2370 \\
\hline Phase angle $\left(^{\circ}\right)$ & 23.8 & 26.0 & 28.0 & 30.5 & 30.9 & 31.1 \\
\hline \multicolumn{7}{c}{ AC } \\
\hline Dynamic modulus (MPa) & 10554 & 7572 & 6285 & 3838 & 3145 & 1942 \\
\hline Phase angle $\left({ }^{\circ}\right)$ & 20.2 & 22.3 & 23.5 & 26.2 & 26.5 & 27.6 \\
\hline
\end{tabular}

Table7 Results of CRM-AC and AC@ the higher temperature

\begin{tabular}{c|c|c|c|c|c|c}
\hline \multicolumn{7}{c}{ CRM-AC } \\
\hline Loading frequency (Hz) & 25 & 10 & 5 & 1 & 0.5 & 0.1 \\
\hline Dynamic modulus (MPa) & 3154 & 2463 & 2058 & 1504 & 1378 & 1146 \\
\hline Phase angle $\left({ }^{\circ}\right)$ & 28.6 & 26.1 & 24.7 & 19.9 & 18.4 & 17.5 \\
\hline \multicolumn{7}{c}{ AC } \\
\hline Dynamic modulus (MPa) & 2127 & 1436 & 1115 & 691 & 605 & 480 \\
\hline Phase angle $\left({ }^{\circ}\right)$ & 36.7 & 33.9 & 32.4 & 26.9 & 23.1 & 18.8 \\
\hline
\end{tabular}

Generally, based on dynamic modulus and phase angle, storage modulus E' and loss modulus E" can be calculated by the formula: $E^{\prime}=\left|E^{*}\right| \sin \delta, E^{\prime \prime}=\left|E^{*}\right| \cos \delta$, as the above table shows. For rheological material, the storage modulus represents elastic characteristic and the loss modulus represents viscoelastic characteristic. For E' and E" at the same temperature, ones of CRM-AC are higher than ones of AC.

For the further study on the rutting resistance and the fatigue resistance of CRM asphalt mixture, the rutting factor $\left(\mathrm{E}^{*} / \sin \delta\right)$ and the fatigue factor $\left(\mathrm{E}^{*} \cdot \cos \delta\right)$ are achieved by SHRP calculation method based on dynamic modulus and phase angle. At $21.1^{\circ} \mathrm{C}$, the rutting factor has no obvious distinguish between CRM-AC and AC, but the fatigue factor of CRM-AC is evidently higher than AC. It indicates that at usual temperature condition, the rutting resistance of CRM-AC is close to AC, but the fatigue resistance of $\mathrm{f} \mathrm{CRM-AC}$ is superior to AC. 
The crumb rubber is very beneficial to improve the fatigue resistance of asphalt mixture with usual temperature state. However, the rutting factor of CRM asphalt mixture is obviously higher than $\mathrm{AC}$ at $40^{\circ} \mathrm{C}$.

\section{Conclusions}

After finished the blending design of CRM mixture, the rutting resistance, cracking resistance, moisture sensitivity, resilient modulus and dynamic modulus of tire crumb modified asphalt mixture are systematically investigated in this paper, and the following conclusions can be drawn:

1) Bituminous mixtures with tire crumb rubber have the better performance of pavement, including rutting resistance, cracking resistance, and moisture sensitivity.

2) However, the gradation of rubber particles needs to be considered in blending design of CRM mixture. And the properties vary with the different crumb rubber content.

3) Moduli test results also indicate that the addition of crumb rubber to asphalt binder generally increased the binder viscosity and improved the resistance of rutting at the higher temperature and the fatigue resistance at the ordinary temperature.

\section{Acknowledgements}

The authors acknowledge the Beijing Road Bureau for financial support of this project. Thanks are expressed to P.E. Hao Liu and Liying Yang for helpful discussions. Thanks are also expressed to Mr. Jianguo Wang and Qian Wang of R\&D center in Beijing municipal R\&B building Material Corporation for specimens' preparation and measurement.

\section{References}

[1] Brown, D. R., Jared, D., Jones, C., and Watson, D. (1997). "Georgia's experience with crumb rubber in hot-mix asphalt." Transportation Research Record. 1583, Transportation Research Board, National Research Council, Washington, D.C., 45-51.

[2] Stroup-Gardiner, M., Chadbourn, B. C., and Newcomb, D. E. (1996). "Babbitt, Minnesota: Case study of pretreated crumb rubber modified asphalt concrete. Transportation Research Record. 1530, Transportation Research Board, National Research Council, Washington, D.C., 34-42.

[3] Maupin, G. W., Jr. (1996). "Hot-mix asphalt rubber applications in Virginia." Transportation Research Record. 1530, Transportation Research Board, National Research Council, Washington, D.C., 18-24.

[4] Charania, E., Cano, J. O., and Schnormeier, R. H. (1991). "Twenty-year study of asphalt rubber pavements in Phoenix, Arizona." Transportation Research Record. 1307, Transportation Research Board, National Research Council, Washington, D.C., 29-38.

[5] Raad, L., and Saboundjian, S. (1998). "Fatigue behavior of rubber modified pavements." Transportation Research Record. 1639, Transportation Research Board, National Research Council, Washington, D.C., 73-82.

[6] Soleymani, H. R., Zhai, H., and Bahia, H. (2004). "Role of modified binders in rheology and damage resistance behavior of asphalt mixtures." Proc., 83rd Annual Meeting of the Transportation Research Board, Washington, D.C., Paper No. 04-3974.

[7] McGennis, R. B. (1995). "Evaluation of physical properties of fine crumb rubber-modified asphalt binders." Transportation Research Record. 1488, Transportation Research Board, National Research Council, Washington, D.C., 62-71.

[8] Billiter, T. C., Davison, R. R., Glover, C. J., and Bullin, J. A. (1997). "Physical properties of asphalt rubber binder." Pet. Sci. Technol., 15(3-4), 205-236. 